\title{
Mixed Acinar-Ductal Carcinoma of the Pancreas
}

National Cancer Institute

\section{Source}

National Cancer Institute. Mixed Acinar-Ductal Carcinoma of the Pancreas. NCI

Thesaurus. Code C95458.

A carcinoma that arises from the pancreas showing either extensive mucin accumulation and acinar neoplastic cells or a mixture of columnar or signet-ring cells and acinar neoplastic cells. 